\title{
Study on the Prevalence of Bovine Frothy Bloat in and Around Kebele Lencha, Tokke Kutaye District, Oromia Region
}

\author{
Tagesu Abdisa* \\ Department of Veterinary Medicine, Ethiopia
}

*Corresponding author: Tagesu Abdisa, Department of Veterinary Medicine, Oromia, Ethiopia

Submission: 侮 November 04, 2017; Published: 眥 January 11, 2018

\begin{abstract}
Ruminal tympany, also known as bloat, is a disease of ruminant animals, characterized by an excessive volume of gas in the rumen, an over distention of the rumenoreticulum with the gases of fermentation either in the form of a persistent foam mixed with the ruminal contents, or in the form of free gas separated from the ingesta. Bloating can be divided into primary (frothy/wet bloat) and secondary tympany (free gas/dry bloat). Foamy bloat occurs when cattle consume feeds that are readily digestible, such as finely ground grains and high-quality alfalfas, clovers and cereal grain forage. This study revealed that the prevalence of frothy bloat in and around Kebele Lencha were $79.3 \%$ and the mortality rate of frothy bloat and prevalence of frothy bloat among the age (adult, young) and sex (males, females of bovine species in and around Kebele Lencha were about $25.4 \%$ and (81.9\%, 66.7\%), $(86 \%, 73.1 \%)$ respectively. Therefore, there was statistically significant difference $(\mathrm{P}<0.05)$ between mortality rates of the frothy bloat in age and sex of bovine species. In generally poor feeding management and presenting animals to high protein rich leguminous plant and forage unto ruminant animals, therefor this study forward some recommend for owner, in order to keep the feeding management and special support for ruminant animals, cause the prevalence of frothy bloat. The objective of this study was to conduct the prevalence, identifying causative agent and prevention of frothy bloat in bovine animals at study area.
\end{abstract}

Keywords: Bloat line; Epidemiology; Frothy bloat; Leguminous plants; Mortality rate; Prevalence

\section{Introduction}

Bloating is a disease that studied in agricultural writing since at least A.D.60. And also English journals of the $18^{\text {th }}$ and $19^{\text {th }}$ centuries describe the disease using various terms like: hoove, hoven, tympany and blow [1]. In past centuries, a bellyful of gas was attributed to a poison, to excessive gas production, or to blockage caused by the excessive consumption of dense feed. These and other explanations were the objects of experimental research in several countries from the 1940 s to the 1960s [2]. In Ethiopia, the term given for bloat is "Bokooksaa" in afan Oromo. The term ruminal tympany is an over distension of the rumen with gas of fermentation either in the form of persistent foam mixed with ruminal contents or in the form of free gas separated from ingesta $[3,4]$.

In healthy cattle the gas is produced about 30 to 50 liters every hour. Gas is produced as a result of microbial fermentation of ingested feeds and it accumulates at the top of the rumen [5]. Ruminants need to frequently rid themselves of these gases, mainly through eructation (belching). Eructation is initiated when receptors in the dorsal sac of the rumen and those in the area surrounding the cardia, the junction between the rumen and the esophagus, are exposed to free gas. The cardia remains tightly closed if exposed to anything other than gas, preventing liquid and particulate matter from entering the lungs. A complex series of contraction of muscle of rumen and reticulum can forces liquid material away from the cardia, creating an empty space for the dorsal sac to push gas forward. The anatomical classification of the forestomach and its ingesta separation is indicated in figure $1 \mathrm{~A}-1 \mathrm{D}$ [6].

Eructated gas travels up the esophagus at 160 to $225 \mathrm{~cm}$ per second [7]. Once surrounded by gas the cardia will relax, which triggers the animal to breathe deeply, drawing gas upwards into the esophagus and lungs, ultimately being expelled through the mouth. This sequence of events should occur approximately once every minute if normal fermentation processes are occurring inside of the rumen [8].

Bloat occurs when ruminants are prevented from expelling ruminal gas, resulting in pressure on the diaphragm and lungs, which affects breathing and potentially results in death. Bloating can be divided into two like primary or frothy/wet bloat and secondary or free gas (dry) bloat [4]. Free-gas bloat, which is typically a result of physical obstruction or damage to the cardia 
(or esophagus) or to decreased ruminal motility, occurs in feedlot cattle, but frothy bloat is a result of the formation of stable foam in the rumen of feedlot cattle can result in the cardia being covered by foam, which inhibits eructation of gas and with the frothy pasture bloat that occurs in ruminants grazing alfalfa or annual winter wheat, a combination of high-forage soluble protein concentrations coupled with rapid fermentation and evolution of gas are thought to contribute to the formation of stable foams [4,9].

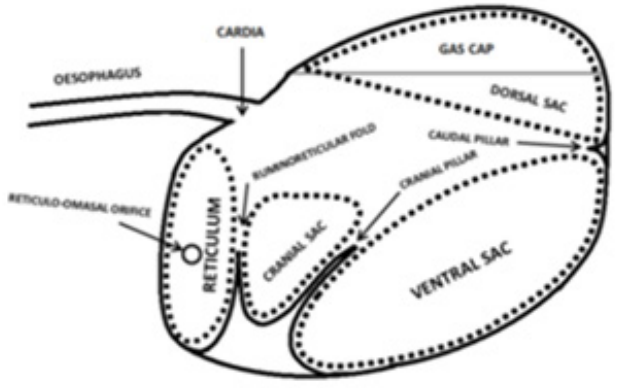

A.

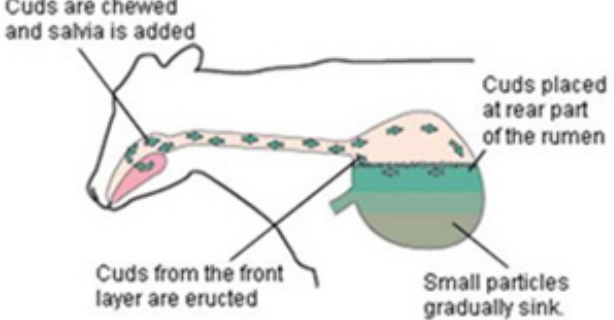

C.

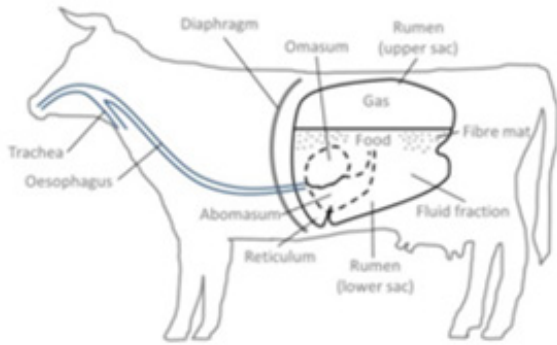

B.

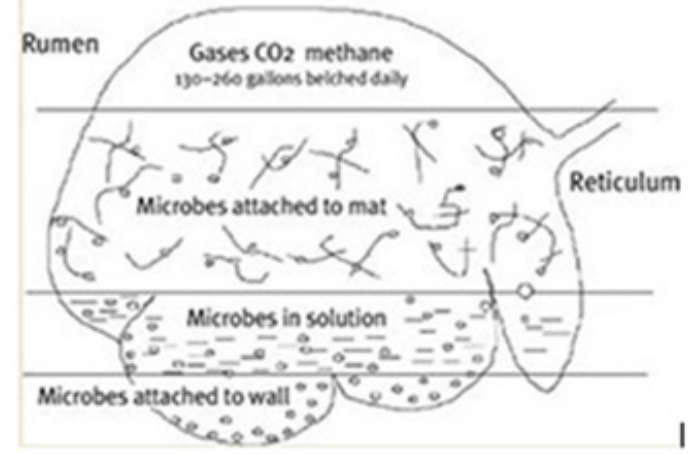

D.

Figure 1: Anatomy and physiology of rumen and its ingesta in ruminants. Figure A Shows the structure of rumen sac; Figure B: Shows the anatomical location of rumen and reticulum. Figre C and D shows, the ingesta and microbial attachement to ingesta.

A. https://www.ecow.co.uk/biology-of-the-rumen.

B. Blowey, R. W. (2006). A veterinary book for dairy farmers (p. 394).

C. http://vet.uga.edu/ivcvm/courses/vpat5215/digestive/week02/forestomach/rumen03.htm.

D. https://www.daf.qld.gov.au/animal-industries/dairy/feed-and-nutrition/nutrition-for-lactating-dairy-cows/rumenmicrobes.)

Free-gas bloat is more often related to rumen atony or physical/pathological problems preventing normal gas eructation and physical obstruction of eructation is caused by esophageal obstruction due to a foreign body (potatoes, apples, turnips, and kiwifruit, boluses ,carrot, tomatoes, some comb of corn and etc.), positional (e.g., being trapped in a position that precludes eructation), tumors, abscesses, enlarged cervical or thoracic lymph nodes, vagal nerve paralysis or injury, traumatic reticulitis, hypocalcemia, and central nervous system conditions affecting eructation reflexes, stenosis, or pressure from enlargement outside the esophagus (as from lymphadenopathy or sporadic juvenile thymic lymphoma) and bovine viral leucosis involvement of bronchial lymph nodes [10,11].

Interference with esophageal groove function in vagal indigestion and diaphragmatic hernia may cause chronic ruminal tympany. This also occurs in tetanus. Tumors and other lesions, such as those caused by infection with Actinomyces bovis, of the esophageal groove or the reticular wall are less common causes of obstructive bloat. There also may be interference with the nerve pathways involved in the eructation reflex. Lesions of the wall of the reticulum (which contains tension receptors and receptors that discriminate between gas, foam, and liquid) may interrupt the normal reflex essential for escape of gas from the rumen. Normal tone and motility of the musculature of the rumen and reticulum are also necessary for eructation. In anaphylaxis, bloat occurs commonly because of ruminalatony and is relieved by the administration of epinephrine or antihistamine drugs $[4,10]$. Possible causes of the ruminalatony and failure of eructation include: esophagitis, acidosis, rumenitis and failure of rumination because of an all-grain diet [4]. 
The vagus nerves, which connect the rumen wall to the central nervous system, pass alongside the esophagus in the neck of the animal. At the rumen, these nerves branch out and spread over the rumen surface. When functioning properly, the vagus nerves convey information from the nerve sensors in the rumen wall to the brain centers and transmit signals from the brain for the control of the muscles in the rumen wall. If the vagus nerves are damaged, information transferred to and from the rumen can be impaired. Depending on the severity of the damage, rumen function can be affected to various degrees. Mild damage may not be visibly expressed in an animal, whereas severe damage may cause an animal to suffer from chronic bloat, feed impaction, lack of appetite, or a combination of these symptoms $[2,12]$. Some toxic plants can cause the paralysis of vagus nerve and reduce ruminal motility that can cause failure of esophagus opening. Nitrate and HCN toxin that produced from the following plants like Sorghum, Sudan's grass, Millets and amaranths can cause bloating in ruminants [13-15]. Clinically, rumen distension will be observed in the left paralumbar fossa. Additional signs may include colic-like pain of the abdomen and dyspnea. Passage of a stomach tube helps to differentiate between free-gas bloat and frothy bloat. Obstructions may require manual removal prior to the use of a stomach tube $[4,16]$. Free gas bloat is just for highlight due to this study concerns with frothy bloat only. Therefore, the main objective of this study is that to coin out the cause and prevalence of frothy bloat in study area and revising on the fact of bovine frothy bloat.

\section{General Description of the Frothy Bloat and Etiology in Bovine Animals}

Foamy bloat occurs when cattle consume feeds that are readily digestible, such as finely ground grains and high-quality alfalfas, clovers and cereal grain forage. Once consumed, these feeds provide readily available nutrients that are immediately utilized by ruminal microbes, leading to a very rapid production of gas in the rumen. The characteristic of foamy bloat is different from free gas in that, the gas is trapped in thick proteinaceous foam. This thick foam prevent animals from expulsion of gas, then animals become bloated [17]. Pasture (frothy) bloat can occur in animals grazing wheat pasture or lush legumes (alfalfa, ladino, white clover) or being fed green-chopped legumes. Feedlot bloat usually refers to bloat in cattle fed high-grain rations that may or may not contain legume forage. It often occurs secondary to acidosis and/ or rumenitis. Cattle consuming feedlot diets may have bloat caused by the grain portion being ground too finely. Fine ground grains are digested rapidly, causing rapid fermentation and gas production $[17,18]$.

\section{Epidemiology}

Pasture bloat occurs in both dairy and beef cattle that graze pastures consisting of bloating forages. The incidence is highest when the pasture is lushest. Spring and autumn are the most dangerous seasons, when the pastures are lush and young and the leaves of the plants contain a high concentration of soluble proteins. Dry hot conditions and matured plants, and thus midsummer, are the forerunners of a decline in incidence. Sheep can also be affected but appear to be much less susceptible than cattle [19].

Under warm wet conditions in spring, a lush green pasture may have the potential to cause bloat conditions in ruminants. In Frothy Bloat, foam forms in the rumen of the ruminants with tiny bubbles that are impossible to belch up. The rumen becomes distended with foam and the goat dies very quickly from circulatory failure due to excessive pressure on the diaphragm. By far, frothy bloat is considered the most dangerous of the three types of bloat [20]. Cooler than normal temperatures (especially at night) are usually associated with bloat. Reasons may include higher forage intake by animals during cool weather and that plants initially are digested more rapidly when grown at lower temperatures. Cattle also tend to bloat more frequently in the morning, possibly because their biggest meal occurs at this time. The factor influencing the incidence of frothy bloat in grazing animals can be categorized into three areas: animal, plant and ruminal factors, soil fertility, climatic conditions, and stage of plant development, grazing management, and animal predisposition among others [21,22].

\section{Animal Factor}

It is fairly well established that young animals are more susceptible to acute and severe bloat than older animals, and it is suspected that animals get used to eating bloating pastures and are less susceptible after exposure [23]. Variation in incidence and severity of bloat between animals grazing the same pasture may be partially related to animal factors such as differences in diet selection, forage intake and saliva production. Increased saliva production may reduce formation and stability of frothy bloat through its potential anti-foaming characteristics, buffering capabilities and effects on rate of passage. Animals highly susceptible to bloat may secrete less saliva and/or have compared with less susceptible animals. Although forage intake would appear to affect an animal's susceptibility to wheat pasture bloat, research remains unclear on the role of forage intake patterns on occurrence of bloat $[4,23]$.

\section{Plant Factors}

Table 1: Forage species and their potential for causing bloat in cattle [2].

\begin{tabular}{|c|c|c|}
\hline High Potential & Low Potential & Considered Safe \\
\hline Alfalfa & Arrow leaf clover & Birds foot trefoil \\
\hline Sweet clover & Spring wheat & Cicermilkvetch \\
\hline Red clover & Oats & Crownvetch \\
\hline White clover & Rape & Lespedeza \\
\hline Alsike clover & Perennial ryegrass & Fall rye \\
\hline Winter wheat & Berseem clover & Most grasses \\
\hline
\end{tabular}

Consumption of legume forages in large quantities is one of the primary causes of frothy bloat; however, not all legumes cause frothy bloat. Legumes can be classify as either bloat causing, or bloat safe as indicated in Table 1. Bloat causing legumes include alfalfa, sweet clover, red clover, ladino clover, white clover, and 
alsike clover [4,8]. First, bloat-safe legumes have thick cell walls which prevents mechanical disruption while animals are chewing. This means that when bloat-safe legumes enter the rumen it will take longer for rumen microorganisms to invade plant tissues, and consequently are they digested very slowly [24].

In addition to mechanical strength of cell walls, bloat-safe legumes have large amounts of condensed tannins, which inhibit frothy bloat. Condensed tannins are plant polyphenols capable of binding soluble proteins responsible for foam production [25].
In contrast, bloat-causing legumes are more vulnerable to being broken down during chewing because of weaker cell walls, allowing rumen microorganism easier access to cellular constituents. One constituent released upon degradation of the mesophyll cell wall is chlorophyll. It is hypothesized the chlorophyll concentration within rumen is the main cause of leguminous associated bloat [26]. Digestion of chlorophyll result in disruption of the lamellar membrane of chloroplasts releasing soluble proteins, namely fractions I and II, which are believed to be the major foaming agents in the rumen [27].

Table 2: The comparison of pasture bloat and feedlot bloat with their foam formation.

\begin{tabular}{|c|c|c|c|}
\hline Features & Feedlot Boat & Pasture Bloat & Function \\
\hline Readily digested feedstuff & High grain ration & Fresh immature forages & $\begin{array}{l}\text { Energy source for bacterial growth } \\
\text { and rapid slime and gas production }\end{array}$ \\
\hline Small particles in rumen content & Fine grain particles & Chloroplast particles & Small particles add to slime matrix. \\
\hline Viscous rumen content & Microbial slime & Microbial particles & Matrix to trap particles and gas. \\
\hline
\end{tabular}

In general, bloat provocative forages are actively growing, highly digestible species with high protein and low fiber contents. These include temperate legumes such as red clover, white clover, and alfalfa, as well as small grains and annual and perennial grasses such as winter wheat. Foamy bloat has been associated with increases in soluble proteins and/or carbohydrates associated with the rapidly growing forage, as well as a more rapid release of plant cell contents in the rumen that leads to a high rate of ruminal gas production. The foam is formed from grain over feeding (formation of slime) and highly soluble proteins that are describe in Table 2. In addition to soluble proteins, mineral content of the grazed forage also has been related to metabolic disorders of animals grazing winter wheat. Research indicates that increased occurrence of bloat is associated with increases in calcium (Ca) and magnesium (Mg) concentrations of legumes, as well as increased potassium (K) and/or potassium: sodium ratios of winter wheat $[25,26]$.

\section{Ruminal Factors}

Microbial factors which contribute to the stability of foam inside the rumen (Figure 1D). In bloated animals it has been noted that rumen bacteria produce an overabundance of mucopolysaccharides that form into a slime in the rumen.This slime increases the viscosity of rumen contents, in addition to stabilizing the gaseous foam [8]. As Coulman et al. (2000) reported that slime is the increase in viscosity which leads to formation of gas into the characteristic bubbles. Frothy feedlot bloat has been attributed to small feed particles in grain rations that cause slime to form in rumen contents. The slime is made up primarily of polysaccharides secreted by rumen bacteria and released from ruptured bacterial cells. The bacterial polysaccharides increase the viscosity of rumen fluid and subsequently trap small gas bubbles in the rumen fluid, leading to frothy rumen contents and bloat $[2,4]$.

Ruminal concentrations of soluble proteins and minerals may not initiate bloat; they are believed to increase the stability of foam in the rumen, potentially increasing the incidence and severity of bloat. Attraction between soluble proteins, which are negatively charged, and positively-charged mineral ions present in rumen fluid can increase the stability and strength of foams. Similar to colloidal suspensions of soils, divalent ( $\mathrm{Ca}$ and $\mathrm{Mg}$ ) and trivalent ions can form bonds with two or three negatively charged protein particles, thereby creating a more stable foam compared with sodium, a monovalent ion. Several trials evaluating legume bloat indicated that ruminal $\mathrm{Ca}, \mathrm{Mg}$ and $\mathrm{K}$ concentrations were significantly higher and Na levels significantly lower in bloating animals, suggesting Na supplementation may reduce the incidence of bloat. Additional wheat pasture bloat research also indicates an increase in occurrence of bloat concurrent with increases in forage potassium levels [2,28,29].

\section{Pathogenesis and Clinical Sign of Frothy (Pasture Bloat)}

Pastured beef cattle are not checked as regularly as dairy cattle, so they are more likely to be found dead when they suffer from bloat. Feedlot cattle that die as a result of bloat are commonly found dead in the morning, possibly because they are inactive during the night or because they are not seen, detected, and treated [30].

Cattle that are milked and observed regularly may begin to become bloated 30 minutes to 1 hour after they are turned out to a bloat-producing pasture. However, there is commonly a lag of 24 to 48 hours before bloating occurs in cattle that have been placed on a bloat-producing pasture for the first time. They may become bloated on the first day, but bloat more commonly occurs on the second or third day [29]. Clinical sign, which observed in pasture (or frothy) bloat, is the distention of abdomen. Distension is usually more obvious in the upper left flank, although the whole of the rumen can be enlarged, as indicated in Figure 2. Some clinical sign is observed like getting up and lying down frequently, defecate frequently, kick at the abdomen and rolling over in attempting to relieve the discomfort. Breathing is difficult or labored (a condition known as dyspnea) and occurs through the mouth. The animal protrudes the tongue, salivates, and extends the head. Its respiratory rate increases to up to 60 inhalation-exhalation cycles per minute. Occasionally, projectile vomiting occurs, and the animal 
may expel soft feces in a stream. Ruminal movements are usually much increased in the early stages and may be almost continuous, but the sounds are less audible because of the frothy nature of the ingesta. Later, when the distension is extreme, the movements are decreased and may be completely absent. The tympanic note or drum sound produced by percussion (tapping on the distended rumen) is characteristic. Before severe bloat (known as clinical tympany) occurs, a temporary increase in eructation and rumination can be noted, but both disappear with severe bloat. Death may occur quickly, but usually does not take place until 2 to 4 hours after the onset of bloat. When the bloat becomes severe enough, the animal collapses and dies quickly, almost without a struggle. Death is likely caused by suffocation, when the distended rumen pushes against the diaphragm and prevents inhalation $[4,30]$.

\section{Clinical Pathology}

Animals that die from bloat have rather characteristic lesions, including congestion and hemorrhages in the cranial thorax, neck and head, and compression of the lungs. Pressure from the distended rumen leads to congestion and hemorrhage of the esophagus in the region of the neck, while the esophagus in the thorax is pale. The anterior regions of the carcase may be very congested due to huge pressure changes and the oesophagus (gullet) may have a "bloat line" (red thoracic portion and pale abdominal portion. Usually, the liver is also pale because of displaced blood and interruption of blood supply. Obvious distension of the rumen is certainly observed in animals that die of bloat, but also occurs rapidly after death from almost any cause in ruminants, and is not a useful diagnostic lesion [31].

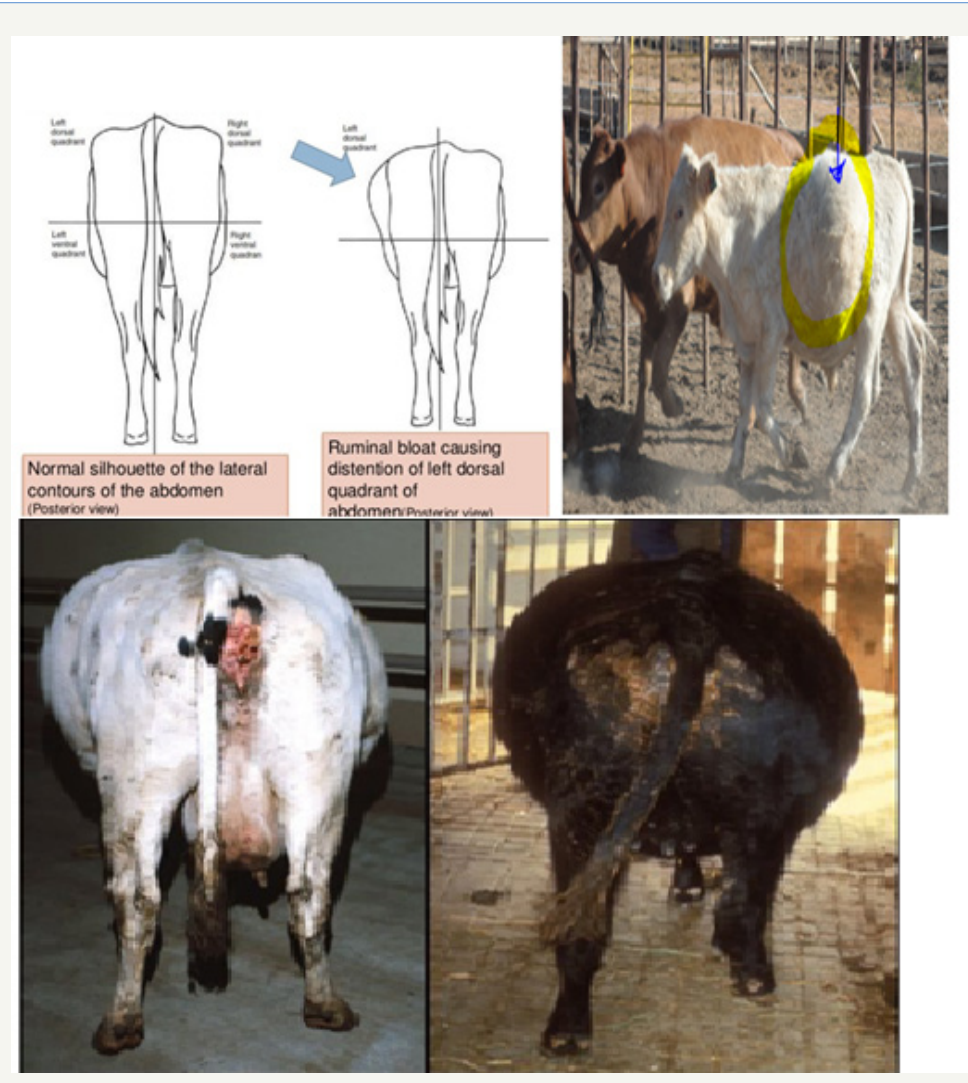

Figure 2: Clinical sign of bloating symmetric which observed from left side (source: http://www.vivo.colostate.edu/hbooks/ pathphys/digestion/herbivores/tympany.html).

Animals that have died from bloat are usually found partly on their backs with legs distended in the air and bloody discharge from body orifices. Distension of the rumen may decline steadily after death and may not be observable after 12 hours so prompt post mortem examination is advisable. Huge increases in intrarumenal pressure results in blood being prevented from returning to the heart and interferes with breathing so animals asphyxiate. Congestion and hemorrhage of the lymph nodes of the head and neck, epicardium, and upper respiratory tract are marked. The lungs are compressed, and intrabronchial hemorrhage may be present. The cervical esophagus is congested and hemorrhagic, but the thoracic portion of the esophagus is pale and blanched the demarcation known as the "bloat line" of the esophagus (Figure 3) [32-34]. The rumen is distended, but the contents usually are much less frothy than before death. The liver is pale because of expulsion of blood from the organ [32].

\section{Diagnosis of Bloating}

Usually, the clinical diagnosis of frothy bloat is obvious. The causes of secondary bloat must be ascertained by clinical examination to determine the cause of the failure of eructation. However diagnosis is depending on theon the clinical signs, history 
of access to lush pasture Passing a stomach tube will distinguish between gassy and frothy bloat. If it's gassy bloat a stomach tube passed into the rumen will allow the gas build-up to escape through the tube. No such gas is seen in frothy bloat $[31,35]$. The best method in diagnosis of bloat animals is using general clinical examination like auscultation and palpation [36]. Under auscultation the sound emitted from rumen is drum like sound Differentiation between frothy and free gas bloat can only be achieved by attempts at decompression and Decompression can be attempted either by using a large 16 BWG $(1.65 \mathrm{~mm}) 5 \mathrm{~cm}$ needle inserted into the tympanic dorsal sac of the rumen through the flank, or by passing a stomach tube into the rumen per os or per nasal. Free gas bloat can easily be decompressed. Frothy bloat simply blocks the tube without decompression and also by palpation of esophagus for obstruction, in frothy bloat there is no esophageal obstruction [37].

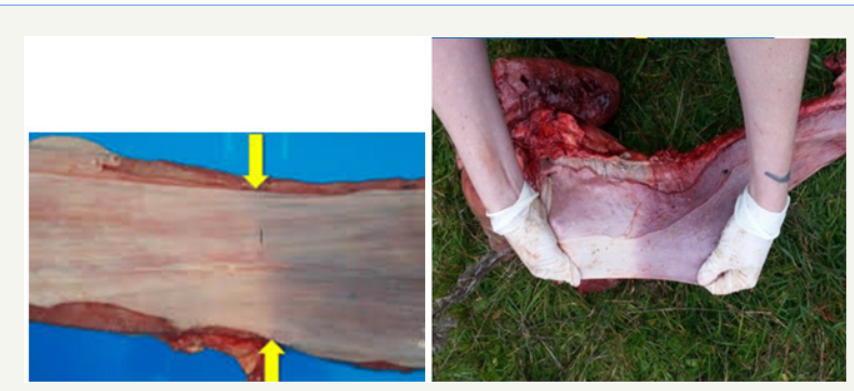

Figure 3: Bloating line observed at the esophageal mucosa from this case of bloat - thoracic portion is white (because of high pressure pushing blood out) and cervical portion is red (because of congestion, blood here cannot get back to the heart).

\section{Treatment}

The approach to treatment depends on the circumstances in which bloat occurs, whether the bloat is frothy or due to free gas, and whether or not the bloat is life threatening [18,30]. For the treatment of bloating in emergence cases stomach tube or rumentomy may be advisable and also the animals have to treated with antifoaming agents like paraffin oil, detergents and antibiotics. In frothy bloat, it may be impossible to reduce the pressure with the tube, and an antifoaming agent should be administered through the stomach tube. A variety of antifoaming agents are effective, including vegetable oils (eg, peanut, corn, soybean) and mineral oils (paraffins), at doses of 250-500mL [30]. Dioctyl sodium sulfosuccinate, a surfactant, is commonly incorporated into one of the above oils and sold as a proprietary antibloat remedy, which is effective if administered early. Poloxalene (25-50g, PO) is effective in treating legume bloat but not feedlot bloat [30]. Placement of a rumen fistula provides short-term relief for cases of free-gas bloat associated with external obstruction of the esophagus $[4,30]$.

In severe cases in which there is gross distension, mouthbreathing with protrusion of the tongue and staggering, an emergency rumenotomy is necessaryto save the life of the animal. Once the animal falls down death occurs within a few minutes and many animals have died unnecessarily because owners are unable or reluctant to do an emergency rumenotomy. Using a sharp knife, a quick incision $10-20 \mathrm{~cm}$ in length is made over the midpoint of the left paralumbar fossa through the skin and abdominal musculature and directly into the rumen, then release the rumen content and suture it [30].

The trocar and cannula have been used for many years for the emergency release of rumen contents and gas in bloat. The anatomical location for incision of skin by trocar and canula is that at flank of cattle behind of last rib (Figure 4). If the trocar is successful in reducing the pressure, the antifoaming agent of choice can be administered through the cannula, which can be left in place until the animal has returned to normal in a few hours. Owners should be advised on the proper use of the trocar and cannula, the method of insertion and the need for a small incision in the skin, and the care of cannulas left in place for several hours or days [30].

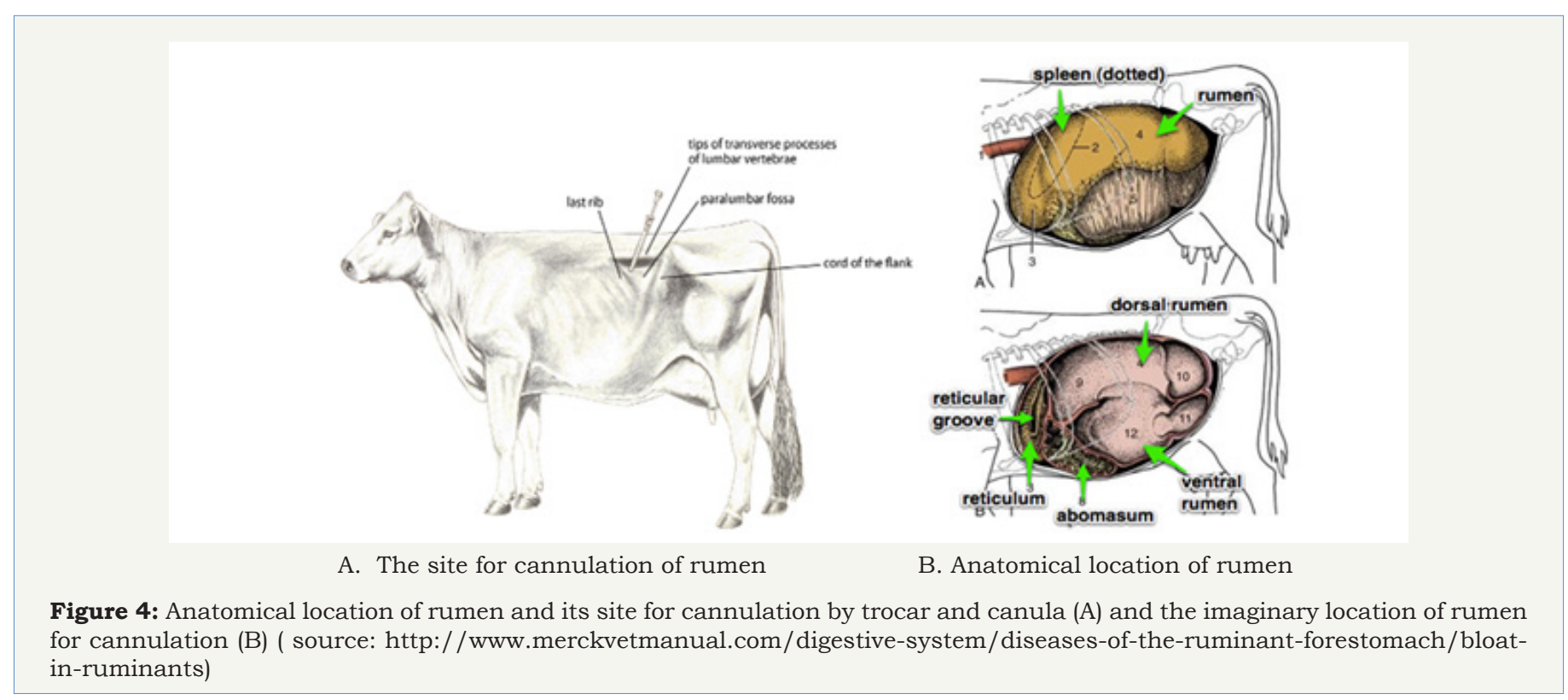

How to cite this article: Tagesu A. Study on the Prevalence of Bovine Frothy Bloat in and Around Kebele Lencha, Tokke Kutaye District, Oromia Region. Appro Poult Dairy \& Vet Sci. 2(3). APDV.000537. 2018. DOI: 10.31031/APDV.2018.02.000537 
Bloating can develop by the action of ruminal microflora like bacteria, fungus and protozoa, that break down the cellulose and protein by microbial fermentation. Therefore antibiotics can control bloat, based on the principle of reduced microbial activity. Penicillin was the first antibiotic used to control legume bloat, but its use was soon discontinued because of the rapid development of microbial resistance to the drug $[8,30]$. The ionophore antibiotics monensin (rumensin) and lasalocid have been used for bloat protection. The mode of cation this ionophores is to alter the permeability of microbial membranes, increase ion transport and change microbial population in rumen and reticulum. Rumensin is formulated in a form of bolus (controlled release capsule). The bolus reduced the incidence of alfalfa bloat by up to $80 \%$; this result was attributed mainly to a reduction of protozoal activity in the rumen. Lasalocid was effective in controlling grain bloat, but not legume bloat. The use of salinomycin has produced conflicting results, with some researchers reporting curative effects and others finding it ineffective for bloat control. When used at rates higher than recommended, ionophore antibiotics can be toxic to cattle [8].

\section{Prevention and management of frothy bloating}

The prevention of pasture bloat is critically difficult; however management practice on pasture is the best for treatment and control of pasture bloat. The practical management may reduce the risk of bloat like feeding hay, particularly orchard grass, before turning cattle on pasture, maintaining grass dominance in the sward, or using strip grazing to restrict intake, with movement of animals to a new strip in the afternoon, not the early morning and also the following list is the best for prevention and control of frothy bloat $[4,8,18,30]$.

If possible avoid using high-risk pastures at high-risk times. Pastures with a history of bloat problems or with a high clover content should not be used for cows soon after turnout. Stagger turnout with buffer feeding as this will allow the rumen to adapt

\section{Material and Methods}

\section{Study area}

Figure 5: Map of study area Tokkekutaye, kebelelencha and its surrounding.

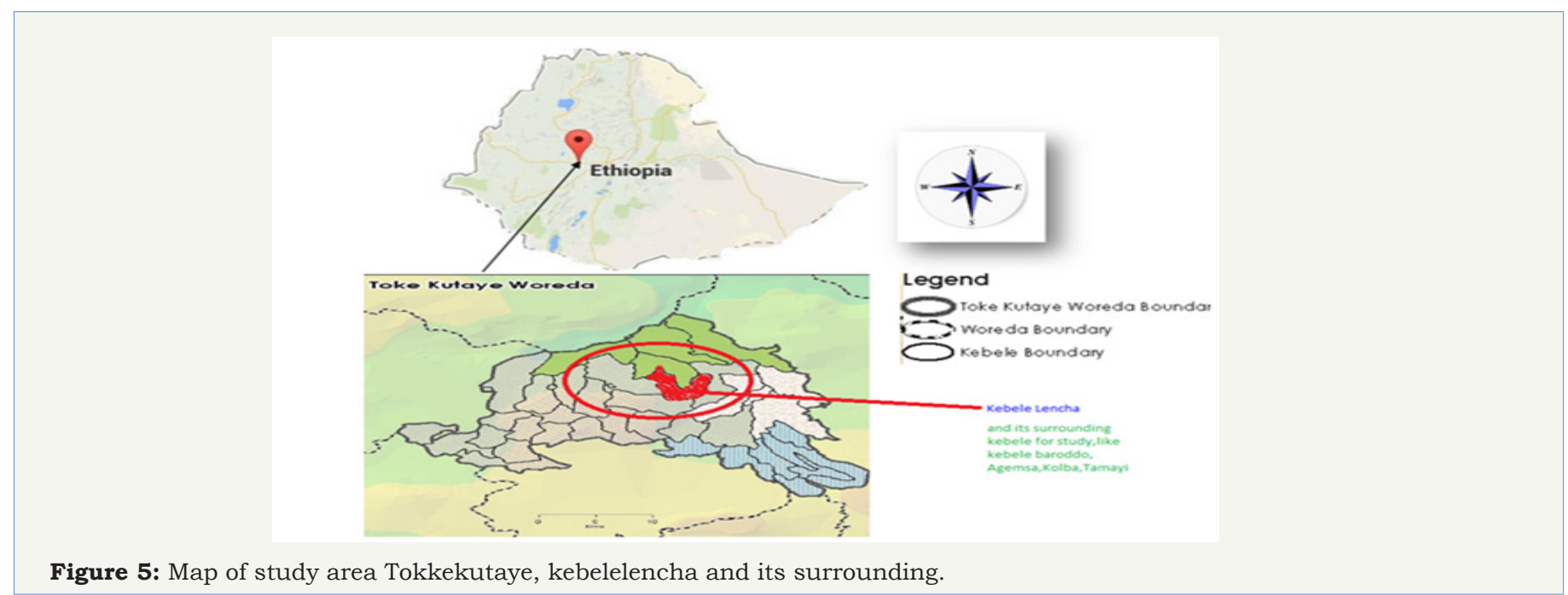

to the new diet. In particular try and keep up fibre intakes at risk periods. If you have to use high-risk pastures, introduce the cattle to them slowly. In some cases restricting access to as little as ten minutes per day at the start may be necessary to prevent bloat. Avoid starting to graze high-risk pastures when they are wet and dew. Administer anti-foaming agents daily if bloat is a severe problem. If this is the case and you can strip graze then spraying antifoaming oils (emulsified with water) onto the grass can significantly reduce labour costs. Remove high-risk animals. Some animals have recurrent bloat despite prevention and treatment. Never turn hungry livestock into a pasture containing a high proportion of bloat-causing plants. Fill animals with dry hay or grass pasture before beginning to graze high bloat-potential pastures. Avoid turning animals onto fresh, high bloat-potential pasture that is moist with dew, rain, or irrigation water.

Both rate of intake and initial rate of digestion are higher from moist plants, causing more rapid initial digestion. Make paddock rotations mid-day or later to help minimize moisture and increase plant carbohydrate concentration. Avoid dramatic changes in forage quality when rotating from paddock to paddock by leaving adequate residue. Observe livestock closely the first several days and remove any "chronic-bloating" animals. Avoid grazing legumes before they begin to bloom. This may not be possible if spring grazing or if grazing season-long. Make closer observations for bloat when many plants are at a younger growth stage. Manage grazing to encourage livestock to consume low- or non-bloating plants and plant parts rather than just succulent top growth. For example, use daily strip grazing or use high stock density in multiple paddock systems rather than continuous stocking. Feedlot bloat that occurs on high concentrate rations usually canbe reduced by providing 15 percent of roughage coarsely chopped and increase the concentration of the ionophores. Also, substitute low quality legume or non-legume roughage for Lucerne hay or adjust the protein, vitamin and minerals supplement appropriate [18,30].

How to cite this article: Tagesu A. Study on the Prevalence of Bovine Frothy Bloat in and Around Kebele Lencha, Tokke Kutaye District, Oromia Region. Appro Poult Dairy \& Vet Sci. 2(3). APDV.000537. 2018. DOI: 10.31031/APDV.2018.02.000537 
The study was conducted in Oromia region, in Tokke Kutaye district, Kebele Lencha. Toke Kuatye is one of the woreda in the Oromia Region of Ethiopia. The woreda was established in January 2006. The capital town for toke kutaye is Guder and located at 12 kilometers west of Ambo [39]. Tokke kutaye is located between $10045^{\prime} \mathrm{N}-10090^{\prime} \mathrm{E}$ and $37050^{\prime} \mathrm{N}$ to $40050^{\prime} \mathrm{E}$. The area is bounded by Caliya and Nonno district in the West, Midaqegn district in the North, Ambo and Wanchi districts in the East, and Dire inchini district in the South. The major parts of Toke kutayeworeda are the part of the central Oromia high lands. The topography of the district is predominately plateau with some small hills in parts of the district. The study was conducted in and around Kebele Lencha, neighbor kebele like Agemsa Dasoo, Barodo,Tamayi and Kolba. The veterinary clinical sector is found in Kebele lencha, Tokke Geba kemisa (Hamus Geba) at $15.7 \mathrm{~km}$ from Guder. The main types of livestock present in Kebelelenchaare cattle, sheep, goats, horses, and donkeys. Cows are the only animal that is milked and the working animals for ploughing are oxen. The equines are cultural used for transportation. The production system of bovine in study area is in traditional way. The common of livestock feed is grass and crop residue. The sources of water for livestock in the wet season are unprotected springs, minor rivers, and seasonal ponds and major rivers in the dry season. The map of study area is Figure 5.

\section{Study animals}

The study was conducted from July 2017 to September 2017 in and around Kebelelencha. The numbers of animals examined during this study were about 174 bovine species like cow, heifer, bull, ox, pregnant cow and calves.

\section{Methods of Animal Examination}

The animals were examined for frothy bloat at the pasture and clinic and the data is collected randomly from the owners and clinic sector. The methods of examination were general examination and postmortem examination. General examination is by using auscultation, palpation and inspection method. Postmortem examination is after the animals are died opening the carcass of died animal and observing the necrotic area around esophagus and vital organs, and also the foamy ingesta which accumulate in rumen.

\section{Data management and analysis}

The data were entered and managed in MS -Excel. All the data analysis was done by Statistical Package for Social Science (SPSS) software version 16. Descriptive statistics such as percentages and frequency distributions were used to describe the nature and the characteristics of data. The prevalence of frothy bloat was analyzed using percentages. The association of different risk factors with the disease was computed by Chi - square $(\chi 2)$ test.

\section{Result}

The animals were examined by the random selection of bovine species from kebele lencha and its surrounding. Out of 174 bovine species, 138 were examined for frothy bloat and the animals died from frothy bloat were about 35 . The present study showed that the over prevalence of frothy bloat in and around kebele lencha was $79.3 \%$ (138/174) as indicated in Table 4.

\section{The prevalence of frothy bloat of bovine species}

The study attempt to show that, if there was difference in prevalence rate of frothy bloat among the sex group of bovine species. The result indicated that there was difference in prevalence rate of frothy bloat between sex groups with prevalence rate of $73.1 \%$ in female and $86.4 \%$ in male bovine species. The association of the prevalence rate of frothy bloat with sex was computed with Chi-square test. There was no statistically significant difference $(\mathrm{P}>0.05)$ between the prevalence rate of frothy bloat and sex groups in bovine species as indicated on Table 3.

Table 3: The prevalence of frothy bloat among the sex of study animals at Lencha kebele and surrounding.

\begin{tabular}{|c|c|c|c|c|}
\hline Sex Group Of Animals & No of Examined Animals & Frothy Bloat & Prevalence & P-Value \\
\hline Male & 81 & 70 & 86.4 & 73.1 \\
\multirow{2}{*}{ Female } & 93 & 68 & 79.3 & \multirow{2}{*}{0.76} \\
\hline Total & 174 & 138 & \\
\hline
\end{tabular}

\section{Prevalence of frothy bloat among the ages of bovine species}

Table 4: The prevalence of froathy bloat among the Ages of study bovine species in Lencha kebele.

\begin{tabular}{|c|c|c|c|}
\hline Age of Animals & $\begin{array}{c}\text { No of Examined } \\
\text { Animals }\end{array}$ & $\begin{array}{c}\text { Positive for Frothy } \\
\text { Bloat }\end{array}$ & $\begin{array}{c}\text { Prevalence in Percent } \\
\text { (\%) }\end{array}$ \\
\hline Adult $(>2$ yrs) & 144 & 118 & 81.9 \\
\hline young & 30 & 20 & 66.7 \\
\hline Total & 174 & 138 & 79.3 \\
\hline
\end{tabular}

Similarly, to sex influence on the prevalence rate of frothy bloat was determined, and it was found that there was difference in the prevalence rate of frothy bloat between age groups. The prevalence rate of frothy bloat that was examined from different age groups was different with different age groups. The prevalence of frothy bloat is highly in adult bovine animals (81.9\%) than young bovine animals $(66.67 \%)$ and there was no highly statistically significant difference $(\mathrm{P}>0.05)$ between prevalence of frothy bloat of bovine species with age groups as indicated on Table 4 . 


\section{The mortality rate of frothy bloat in bovine species compared with free gas bloat}

The study was attempted to show the mortality rate of frothy bloat in study area. This study revealed that frothy bloat is the most common and high mortality rate compared to free gas bloat in bovine species. The mortality rate of frothy bloat was $25.36 \%$ and free gas was $19.44 \%$.Therefore, there was highly statistically significant difference $(\mathrm{P}<0.05)$ between mortality rates of the frothy bloat and free gas in bovine species as indicated on Table 5.

Table 5: The mortality rate and prevalence of frothy bloat in bovine species at kebelelencha and its surrounding.

\begin{tabular}{|c|c|c|c|c|c|}
\hline Types of Bloat & $\begin{array}{c}\text { No of Examined } \\
\text { Animals }\end{array}$ & $\begin{array}{c}\text { Number of Dead } \\
\text { Animals }\end{array}$ & Prevalence in \% & Mortality Rate in \% & P-Value \\
\hline Frothy & 138 & 35 & 79.31 & 25.36 \\
\hline Freegas & 36 & 7 & 20.7 & 19.4 \\
\hline Total & 174 & 42 & 24.14 & 44.81 \\
\hline
\end{tabular}

\section{Discussion}

Frothy bloat is the most common noninfectious disease in bovine species than other ruminant animals. The reason behind is that bovine species grazes all grasses and toxic plants, this animals can safer from frothy and free gas bloat. Bovine species unlike small ruminants like sheep and goat, these animals are selecting and browsing the grasses for their feeding. Therefore, the shoats are relatively less susceptible to frothy bloat than bovine species. The present study on frothy bloat of bovine species revealed that, the prevalence of froathy bloat were $79.3 \%$ and mortality rate of froathy bloat in kebele lencha were $20.67 \%$. The mortality rate of frothy bloat is most common in ruminant animals than freegas bloat. The pasture bloat is the common pasture bovine than ovine species.

This study revealed that the adult animals are the more susceptible to froathy bloat, due to the present to grassing in morning before sunrise. In the present study, the overall frequency of frothy bloat were $79.3 \%$, this result contradicts with the findings of [40] who reported the overall prevalence of $11.7 \%$ in Gondor veterinary clinic. Bloating occurs frequently in bovine species due to most of the time bovine graze bloat prone pastures, highly protein containing pasture in wet season, at this season the clover can be occurred. No other research has been conducted in Ethiopia on frothy bloat in bovine but, as Hana et al. [40] reported in Gondor University the prevalence of bloat is $11.3 \%$.

The current study showed that the high prevalence of frothy bloat and its impact on economy, animals are dying; however, the research center and some Veterinary sector did not focus on the awareness and treatment of non-infectious digestive disease of bovine species. When the animals are grazing over the pasture, the owners did not know any think about how to relief the animals during emergency time. But they used the knife to puncture the animal during severe case of frothy bloat and also no effective drug available over veterinary clinical sector in Oromia, Ethiopia. This all side weakness causes the increment of mortality rate among bovine species in study area and decresing the economy of the country.

\section{Conclusion}

Frothy bloat is the common disease in bovine animals, which decrease production of animals and economy. The bovine animals are dying suddenly in the pasture without having any treatment; therefore, the veterinarian and other sector should have to manage the health of animals. In generally, frothy bloats have the characteristic by over distention of ruminant abdomen and not relief only by trocar and canula, but with antifoam drugs. The susceptibility of individual cattle to bloat varies and is genetically determined. The study on prevalence of frothy bloat conducted using the general examination of live and dead animals in and Kebele lencha revealed that, prevalence of frothy bloat and free gas were $79.3 \%$ and $20.7 \%$ respectively. And also this study revealed the mortality rate of frothy bloat and prevalence of frothy bloat among the age (adult, young) and sex (males, females of bovine species in and around kebele lencha were about $25.4 \%$ and (81.9\%, $66.7 \%$ ), ( $86 \%, 73.1 \%$ ) respectively. The risk of frothy bloat is huge on decreasing the economy of developing country. The control and prevention for frothy bloat is generally by practical feeding management for bovine animals and admistering the appropriate drugs for ruminants. There for the objective of this study is to coin out the prevalence and risk factor of frothy bloat in bovine animals and giving some future question on frothy bloat. And also this study revealed the mortality rate and failure of economic loss by frothy bloat in study area.

\section{Acknowledgement}

First of all, I praise my almight God for he loved, guided and helped me in all my life. I would like to express my appreciation for my family for they support me until all my academic education. Lastly, I have respect and thanks for Jimma University College of agriculture and veterinary medicine for they support me in internet access.

\section{Conflict Interest}

I have not any conflict interest with in my research.

\section{References}

1. Howarth RE, Chaplin RK, Cheng KJ, Goplen BP, Hall JW, et al. (1991) Bloat in cattle. Agriculture Canada Publication 1858/E, p. 34.

2. Majak W, McAllister TA, McCartney D, Stanford K, Cheng KJ (2003) Bloat in Cattle. AARD pp. 1-28.

3. Hinchcliff KW, Done SH, Gruenberg W (2016) Chapter 8: Diseases of the alimentary tract-ruminants. Ruminaltympany (bloat). Veterinary Medicine: A textbook of the diseases of cattle, horses, sheep, pigs and goats $\left(11^{\text {th }}\right.$ edn.). Elsevier Health Sciences pp. 473-482. 
4. Aiello SE, Moses MA (2016) The Merck veterinary manual. John Wiley \& Sons.

5. Bowen R (1996). Rumen physiology and rumination.

6. Findlay ALR (1998) Motility of the gastrointestinal tract of ruminants.

7. Stevens CE, Sellers AF (1960) Pressure events in bovine esophagus and reticulorumen associated with eructation, deglutition and regurgitation. American Journal of Physiology-Legacy Content 199(3): 598-602.

8. Majak W, McAllister TA, McCartney D, Stanford K, Cheng KJ (2003) Bloat in cattle. Alberta Agriculture, Food and Rural Development pp. 1-28.

9. Cheng KJ, McAllister TA, Popp JD, Hristov AN, Mir Z, et al. (1998) Areview of bloat in feedlot cattle. J Anim Sci 76(1): 299-308.

10. Ruminal Tympany (Bloat).

11. Fox JG (2015) Laboratory animal medicine. Elsevier. Journal of the American Veterinary Medical Association, Laboratory Animal Medicine ( $3^{\text {rd }}$ edn).

12. Hall JW, Cheeke PR, Majak W (1989) Plant and animal factors in legume bloat. Toxicants of plant origin. Proteins and amino acids. CRC Press, Boca Raton, Fla, USA, 3: 93-106.

13. Abera D, Jibat T, Sori T, Feyisa A, Beyene T (2014) Assessment of Plant and Chemical Poisoning In Livestock in Central Ethiopia. J Environ Anal Toxicol 4: p. 215.

14. Rogers P (1999) Poisoning in cattle and sheep by urea, nitrates and nitrites : Sources, toxic doses, treatment and prevention.

15. Toxic plant for cattle.

16. Ismail ZB, Al-Majali A, Al-Qudah K (2007) Clinical and surgical findings and outcome following rumenotomy in adult dairy cattle affected with recurrent rumen tympany associated with non-metallic foreign bodies. The American Journal of Animal and Veterinary Sciences 2(3): 66-71.

17. Foamy Pasture Bloat.

18. Rick JR, Anderson BE, Randle RF (2010) Bloat Prevention and Treatment in Cattle. IANR pp. 1-4.

19. Berg BP, Majak W, McAllister TA, Hall JW, McCartney D, et al. (2000) Bloat in cattle grazing alfalfa cultivars selected for a low initial rate of digestion: A review. Canadian Journal of Plant Science 80(3): 493-502.

20. Bloat in Ruminants.

21. Foamy Pasture Bloat.

22. McCollum T (2012) Pasture Bloat.
23. Rutter SM, Orr RJ, Yarrow NH, Champion RA (2004) Dietary preference of dairy heifers grazing ryegrass and white clover, with and without an anti-bloat treatment. Applied Animal Behaviour Science 85(1-2): 1-10.

24. Howarth RE, Goplen BP, Fay JP, Cheng KJ (1979) Digestion of bloatcausing and bloat-safe legumes. Ann Rech Vet 10(2-3): 332-334.

25. Coulman BE, Gruber M, McAllister TA, Majak W, Thompson D (2000). American Forage and Grassland Council. Proceedings 9: 351-358.

26. Majak W, Hall KW, Rode LM, Kalnin CM (1986) Rumen clearance rates in relation to the occurrence of alfalfa bloat in cattle. 1. Passage of water soluble markers. J Dairy Sci 69(6): 1560-1567

27. Howarth RE (1975) A review of bloat in cattle. Can Vet Jour 16(10): 281294.

28. Akins MS (2008) Nutritive value of fall-grown cereal-grain forages and effect of wheat type on incidence of bloat in cattle. University of Arkansas, ProQuest Dissertations Publishing, New Jersey, USA.

29. Robinson SE, Clare SG, Leahy MD (1990) Pasture production. Ministry of Agriculture and Food, Canada, pp. 1-73.

30. Radostits OM, Gay CC, Hinchclitt KW, Constable PD (2010) Veterinary Medicine, a Text Book of the Disease of Cattle, Horses, Sheep, Goats, and Pigs. (10 ${ }^{\text {th }}$ edn), Elsevier, New York, pp. 1516-1579.

31. Ruminal Tympany (Bloat, Hoven).

32. Frothy Bloat In Cattle.

33. McGavin MD, Carlton WW, Zachary JF (2001) Thomson's special veterinary pathology.

34. Digestive pathology (2013)

35. Bloat in cattle (2007)

36. Abdisa T (2017) Review on Practical Guidance of Veterinary Clinical Diagnostic Approach. Int J Vet Sci Res 3(1): 006-025

37. Jackson P, Cockcroft P (2002) Clinical Examination of Farm Animals. Blackwell Science, UK.

38. Bloat prevention and treatment.

39. Oromiya Bureau of Finance and Economic Development(OBoFED) (2007) Physical and socio economic profile of Amaya woreda of south west shewa zone, Addis Ababa.

40. Tesfaye H, Belete M, Leta S, Ayele B, Negash A, et al. (2016) Digestive Tract Problems and Their Therapeutic Management in Gondar University Veterinary Teaching Clinic. World Journal of Agricultural Sciences 12(4): 276-281. 